This item was submitted to Loughborough's Research Repository by the author.

Items in Figshare are protected by copyright, with all rights reserved, unless otherwise indicated.

\title{
Ordered search and equilibrium obfuscation
}

PLEASE CITE THE PUBLISHED VERSION

http://dx.doi.org/10.1016/j.jindorg.2009.12.001

PUBLISHER

(c) Elsevier

LICENCE

CC BY-NC-ND 4.0

REPOSITORY RECORD

Wilson, Chris M.. 2019. "Ordered Search and Equilibrium Obfuscation". figshare. https://hdl.handle.net/2134/15286. 
This item was submitted to Loughborough's Institutional Repository (https://dspace.lboro.ac.uk/) by the author and is made available under the following Creative Commons Licence conditions.

\section{creative
commons}

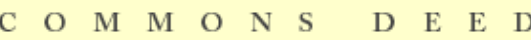

Attribution-NonCommercial-NoDerivs 2.5

You are free:

- to copy, distribute, display, and perform the work

Under the following conditions:

Attribution. You must attribute the work in the manner specified b the author or licensor.

Noncommercial. You may not use this work for commercial purposes.

No Derivative Works. You may not alter, transform, or build upon this work.

- For any reuse or distribution, you must make clear to others the license terms of this work.

- Any of these conditions can be waived if you get permission from the copyright holder.

Your fair use and other rights are in no way affected by the above.

This is a human-readable summary of the Leqal Code (the full license).

\section{Disclaimer 만}

For the full text of this licence, please go to: http://creativecommons.org/licenses/by-nc-nd/2.5/ 


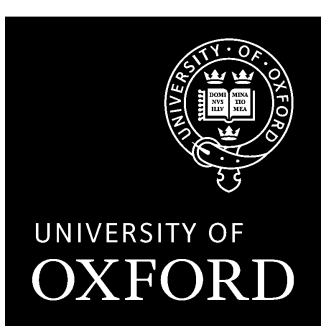

\title{
DEPARTMENT OF ECONOMICS DISCUSSION PAPER SERIES
}

\section{ORDERED SEARCH AND EQUILIBRIUM OBFUSCATION}

\author{
Chris M. Wilson
}




\title{
Ordered Search and Equilibrium Obfuscation
}

\author{
Chris M. Wilson, Loughborough University*
}

First Version: August 2008

This Version: May 2009

\begin{abstract}
This paper demonstrates the incentives for an oligopolist to obfuscate by deliberately increasing the cost with which consumers can locate its product and price. Consumers are allowed to choose the optimal order in which to search firms and firms are able to influence this order through their choice of search costs and prices. Competition does not ensure market transparency - equilibrium search costs are positive and asymmetric across firms. Intuitively, an obfuscating firm can soften the competition for consumers with low time costs by inducing the remaining consumers to optimally first search its rival.
\end{abstract}

\section{Introduction}

This paper studies the strategic incentives for an oligopolist to obfuscate by increasing the cost at which consumers can locate its product and price. In contrast to the standard logic of perfect information disclosure (Grossman 1981, Milgrom 1981), the paper demonstrates a mechanism whereby an individual firm can profitably soften competition by committing to increase its cost of being searched. In equilibrium, firms vary in their provision of information such that search costs are positive and asymmetric.

As one application, the paper can help understand why a single firm, Direct Line, decided to withdraw from all price comparison sites in the UK car insurance market. Contrary to the popular explanation of lowering commission costs, commentators have suggested such savings would have been far outweighed by the costs that followed from

*I thank John Vickers, Mikhail Drugov, Luke Garrod, Marco Haan, Morten Hviid, José Luis MoragaGonzález, Marïelle Non, Eric Rasmusen, Matthew Olczak, Andrew Rhodes, Matthijs Wildenbeest, Alex Wolinzky and the seminar participants at Oxford and Groningen for their comments. Any errors are my own. The financial support of the Economic and Social Research Council (UK) award PTA-026-27-1262 is gratefully acknowledged. Contact details: c.m.wilson@lboro.ac.uk 
the firm's decision to heavily advertise its withdrawal. Instead, the choice of Direct Line to publicly commit to increasing the time required for consumers to locate its prices while maintaining a low-price strategy appears consistent with the obfuscation mechanism documented in this paper ${ }^{1}$. More generally, the insights of the paper can be applied to a range of contexts. They can provide a reason for why some firms may be unwilling to pay for prominent positions in search engine results or directories ${ }^{2}$, why some firms locate in obscure locations, or why firms can vary in their advertising intensity and content.

The paper makes two main contributions. First, by showing that positive, asymmetric search costs may be the outcome of an endogenous market process, it adds support to the importance of search models, but offers some concern over the frequency with which such models assume that search costs are symmetric across firms (e.g. Varian 1980, Stahl 1989 and Janssen and Moraga-González 2004). Second, to analyse these issues, the paper makes an original step by allowing consumers to choose not only the number of firms to search, but also the order in which to search them. Several recent models have stressed the significance of search order, but assume that the order is either exogenous (Arbatskaya 2007, Armstrong et al 2009), or based on relative advertising levels (Haan and MoragaGonzález 2009) ${ }^{3}$. Here, the paper allows consumers to choose their optimal search order and lets firms influence this order through their choice of search costs and prices.

Specifically, the model considers a homogenous good duopoly where consumers either have positive or zero per-unit costs of time. In a first stage, firms select the length of time required to locate their product and price. In a second stage, their decisions becomes common knowledge and the firms then choose prices while consumers decide the extent and order with which they wish to search the firms. If the time required to locate products and prices is assumed to be non-zero and equal across firms, as within standard search

\footnotetext{
${ }^{1}$ Statements about Direct Line's withdrawal decision can be read, together with statements about its price strategy, such as 'Direct Line offers a range of discounts and product innovations that are aimed at achieving one thing - bringing down the cost of car insurance', at http://www.directline.com/motor/welcome.htm and http://www.directline.com/motor/newimprovedcar.htm respectively, 20 April 2009. For the commentators' views, see The Economist, 7 February 2009, p.32.

${ }^{2}$ Athey and Ellison (2008) incorporate consumer search into a model where firms bid for a search engine's sponsored link positions. Their assumptions of exogenous product quality and positive search costs for all consumers rule out any obfuscation results related to this paper.

${ }^{3}$ In a related vein, Hortaçsu and Syverson (2004) demonstrate that asymmetric sampling probabilities are useful in explaining pricing patterns in the mutual funds industry.
} 
models, the firms employ identical mixed-strategy pricing distributions in order to resolve the tensions produced by the consumer heterogeneity. When, however, firms are allowed to pre-commit to the time required to locate their products and prices, an equilibrium exists where one firm obfuscates and where the other, now 'prominent', firm does not.

Intuitively, the act of obfuscation by any given firm induces (the majority of) consumers with positive time costs to optimally first search its rival and makes them less willing to make a second search. This increases the rival's incentives to raise its price (distribution) and benefits the obfuscating firm by softening the competition for the remaining consumers with zero time costs. The prominent firm faces no incentive to raise its search cost in addition to its rival as this can only reduce its profits by deterring consumers from entering the market. Nor does the prominent firm face any incentive to counter the obfuscating firm's strategy by providing consumers with information about its rival because the obfuscation raises both firms' prices and profits (while decreasing all consumers' expected surplus).

After demonstrating how the incentive to obfuscate can extend to situations where there is some minimum level of market friction or more than two firms, the final section of the paper explores the model's two central assumptions. The first of these involves the ability of consumers to observe the length of time required to locate each firm's product and price before making their search decisions. For example, in many everday circumstances, consumers can be aware of the location of each firms' store or website and yet still need to make a costly visit to learn either firm's price. If one weakens such an assumption, the role of optimal search order can no longer be studied as consumers must then view the firms as ex ante identical. However, we proceed to show how obfuscation can remain an equilibrium phenomenon when consumers only observe the firms' decisions imperfectly. The second central assumption involves the ability of firms to pre-commit to an obfuscation strategy. This assumption is shown to be crucial within the model. Without it, a no-obfuscation equilibrium exists where an increase in search costs is incapable of inducing higher rival prices and simply prompts consumers to search and buy elsewhere. Consequently, the model is best applied to the use of longer-run decision variables such as location or certain forms of advertising. In alternative market scenarios where these assumptions may not apply so readily, Ellison and Wolitzky (2008) show how obfuscation can exist if one makes some additional modelling assumptions. In a recent and indepen- 
dent piece of work, they demonstrate the possibility of two obfuscation mechanisms that both differ to this paper within a one-stage framework where consumers do not observe search costs such that search order is not an important issue. Their results are further discussed in Section 5 .

The wider literature dates back to a pioneering paper by Bakos (1997) which emphasised the possibility that firms have an incentive to soften competition by collectively increasing search $\operatorname{costs}^{4}$. More recently however, the literature stemming from Ellison and Ellison (2009) has focused on understanding whether the incentives to obfuscate can extend to the level of an individual firm. The mechanism presented in this paper differs from previous findings in several key respects ${ }^{5}$.

First, the incentive to obfuscate is driven by strategic rather than cost factors. Janssen and Non (2008) present a model of advertising that one can interpret in terms of obfuscation. In a duopoly game where advertising and pricing decisions are simultaneous, firms can either engage in costly advertising to reduce search costs to zero or maintain positive search costs by choosing not to advertise (obfuscate). They find that a pure-strategy zero search cost equilibrium cannot exist because the resulting Bertrand competition would generate an incentive to refrain from costly advertising. However, as advertising costs tend to zero, this incentive to obfuscate vanishes, and the probability that equilibrium search costs are zero tends to one. In our model, firms can select any level of search costs at zero cost.

Second, the incentive to obfuscate does not rely on consumers' bounded rationality. Gabaix and Laibson (2006) present an equilibrium where all firms obfuscate by shrouding a high price for an add-on good. A fraction of myopic consumers do not foresee the existence of add-ons and compare firms only on the basis of observable base prices alone. This leads firms to profitably conceal high add-on prices and cross-subsidise low base good prices $^{6}$. In our model, all consumers are fully rational.

\footnotetext{
${ }^{4}$ Carlin (2008) studies a model where individual obfusction has the implicit effect of increasing all firms' search costs such that the fraction of informed consumers shrinks. Firms obfuscate with positive probability in equilibrium.

${ }^{5}$ Aside from providing an insightful discussion, Ellison and Ellison (2009) use data from the online computer memory market to document how firms use low quality products to maniuplate search engine results and to provide evidence for Ellison (2005), see below.

${ }^{6}$ In a related paper, where firms are presented with the option to set hidden fees on top of observable prices, Garrod (2007) shows that, if some consumers are naive, no equilibrium exists where all firms
} 
Third, the incentive to obfuscate does not rely on the existence of add-on goods. Ellison (2005) offers a model where rational consumers are of either high or low type, with high types being less likely to switch between firms and more willing to purchase add-ons. The concealment of add-on prices acts to soften competition due to an adverse selection effect where firms are deterred from reducing base prices by the possibility of attracting a disproportionate amount of low-types who only buy the base good at a below optimum price. Our model uses a standard, single good framework.

Most closely related to the current paper are the results of Ireland (1993) and Zettelmeyer (2000) who both allow firms to pre-commit to strategies that influence the cost at which consumers can obtain information. In Ireland, each firm pre-commits to informing a proportion of consumers of the firm's existence. Consumers may only buy from firms that they are aware of (at zero cost). In equilibrium, only one firm chooses to inform the entire market. In Zettelmeyer's duopoly model, consumers observe prices but must search to discover their firm-specific product match value as a draw from an exogenous, symmetric distribution. Example parameters can be chosen such that only one firm pre-commits to zero search costs. While this framework simplifies the analysis of consumers' search decisions - consumers simply first search the firm with the lowest search cost - it also makes the equilibrium analysis intractable for a general set of parameters. By allowing consumers to search over endogenous price distributions, our framework provides a tractable equilibrium analysis and offers a more meaningful and fuller investigation of optimal search order.

The paper continues by outlining the model in Section 2 and analysing its equilibria in Sections 3 and 4 . Section 5 investigates the robustness of the results. Section 6 concludes.

\section{THE ModeL}

Let there be two firms, $i=1,2$, that each sell a single homogeneous good at zero production costs to a unit mass of fully rational consumers who each have a unit demand and a maximum willingness to pay of $V>0$. In order to buy from firm $i$, it is assumed that a consumer must necessarily incur $s_{i}$ units of time searching for the location of firm $i$ 's product and price. Consumers vary in their per-unit cost of time and remain indistinguishable to firms. In particular, an extreme form of consumer heterogeneity is introduced commit to zero fees. 
by assuming that a proportion of consumers, $\alpha \in(0,1)$, labelled as 'costly-shoppers', have a positive cost of time that is normalised to unity, and the remaining proportion of 'shoppers', $\beta=1-\alpha$, have a zero cost of time (or enjoy shopping) such that they always choose to search. Consequently, while costly-shoppers face a search cost for firm $i$ equal to $s_{i}$, shoppers always face zero search costs.

Consider the following two-stage game. In Stage 1, each firm simultaneously selects its own search cost, $s_{i}$, by choosing the length of time required to locate its product and price $^{7}$. To ensure that the results are not influenced by any cost motivations, it is assumed that firms may influence their own search costs at zero cost. Firms are free to select any non-negative level of search costs, $s_{i} \geq 0$.

In Stage 2, each firm's choice of search cost becomes common knowledge. The players then choose the following strategies simultaneously. Firms select their own (possibly degenerate) pricing distribution, $F_{i}(p)$, with support $\left[\underline{p}_{i}, \bar{p}_{i}\right]$, from which a price is drawn, $p_{i}$, and the two types of consumers form conjectures about the firms' pricing strategies (which are correct in equilibrium) and select their optimal search strategies. It is assumed that consumers can search the firms sequentially with costless recall. Consequently, a search strategy must prescribe the conditions under which a consumer should make a first search, the conditions under which a consumer should stop searching, and in an important contrast to standard symmetric models, the order in which the consumer should search the firms.

\section{Stage 2 Analysis}

3.1. Optimal Search Strategies. This section begins to analyse Stage 2 by considering consumers' optimal search strategies for a given set of search costs and pricing strategies. While the optimal behaviour of the shoppers simply involves buying from the firm with the lowest price realisation (if lower or equal to $V$ ), and randomising in the case of a price tie, the costly-shoppers' optimal search strategy is more complicated. To characterise their optimal search strategy, we rely on Weitzman (1979) which presents the solution to a generalised dynamic search problem akin to the one considered here. His results imply that the costly shoppers' optimal search strategy can be simplified to three rules

\footnotetext{
${ }^{7}$ One may wish to think of interpretations other than time. Instead, consumers could differ, say, in their cost of effort and firms would then choose the effort required to find their product and price.
} 
that are based on the firms' reservation prices. As in standard search problems, the reservation price of firm $i, r_{i}^{*}$, is defined as the value of $r_{i}$ that satisfies $\int_{p_{i}}^{r_{i}}\left(r_{i}-p\right) d F_{i}(p)=s_{i}$. Intuitively, $r_{i}^{*}$, forms an index of the net gains from searching a given firm $i$ and can be understood as the level of a (fictitious) previously discovered price at which a costlyshopper would view the marginal benefit of searching firm $i, \int_{\underline{p_{i}}}^{r_{i}}\left(r_{i}-p\right) d F_{i}(p)$, as equal to its marginal cost, $s_{i}$. While a firm's reservation price is increasing in its search cost, there is no necessary relationship between a firm's reservation price and its expected price. Instead, reservation prices may be ranked in terms of first-order stochastic dominance, such that $r_{i} \leq r_{j}$ if $F_{i}(p) \geq F_{j}(p) \forall p$ and $s_{i}=s_{j}$. Lemma 1 is presented for the general case of $n$ firms.

Lemma 1. Given the firms' search costs, $s_{i}$, and correct conjectures about the firms' pricing distributions, $F_{i}(p), \forall i=1, \ldots n$, the costly-shoppers' optimal search strategy employs the following three rules, where the reservation price of firm $i, r_{i}^{*}$, is the value of $r_{i}$ that satisfies $\int_{\underline{p_{i}}}^{r_{i}}\left(r_{i}-p\right) d F_{i}(p)=s_{i}$ :

Start Rule: Start search only when the outside option price of $V$ is higher than (or equal to) the lowest reservation price, $\min \left\{r_{1}^{*}, \ldots r_{n}^{*}\right\}$.

Selection Rule: If a firm is to be searched, it should be the unsearched firm with the lowest reservation price.

Stopping Rule: Continue to search only when i) all previously discovered prices and ii) the outside option price of $V$ are higher than (or equal to) the lowest reservation price from the remaining unsearched firms. Otherwise stop and buy at current firm, provided $p \leq V$.

Proof. See Weitzman (1979).

Lemma 1 suggests that the costly-shoppers' optimal search strategy is surprisingly simple. For the standard symmetric case, where $r_{i}^{*}=r^{*} \forall i$, the optimal strategy collapses into the familiar result - costly-shoppers should begin search only if the common reservation price is lower than (or equal to) their valuation, $V$, select any firm to search at random and stop searching and buy only on the discovery of a price lower than (or equal to) the common reservation price, $r^{*}$, and their valuation, $V$. For the asymmetric case, Weitzman's logic implies that a costly-shopper should now begin search only if the lowest 
reservation price is lower than (or equal to) their valuation $V$, select the firms to search in order of ascending reservation prices and stop searching and buy if a price is found that is lower than (or equal to) all the reservation prices of the remaining unsearched firms and their valuation, $V$.

In most cases within the current two firm context, it will later be shown that $\min \left\{r_{1}^{*}, r_{2}^{*}\right\} \leq$ $V$ is true in equilibrium such that the costly-shoppers are willing to make a first search. Lemma 1 then implies that they will strictly prefer to first search firm $i$ iff $r_{i}^{*}<r_{j}^{*}$, be indifferent between first searching firm $i$ and firm $j$ iff $r_{i}^{*}=r_{j}^{*}$, and strictly prefer to stop searching and buy after first searching firm $i$, when $p_{i}<r_{j}^{*}, V$.

3.2. Optimal Pricing Strategies. Having established the consumers' optimal strategies, the analysis of Stage 2 is now completed by characterising the firms' optimal pricing strategies for an exogenous level of search costs. It is well known that the existence of an atom of shoppers will provide the incentive for firms to deviate from any pure strategy pricing equilibrium (e.g. Varian 1980, Proposition 2) and equilibrium pricing strategies are allowed to be in the form of price distributions. In particular, any Stage 2 Nash equilibrium must satisfy the following conditions: given the behaviour of all other players, i) all consumers' search strategies must be optimal, ii) each firm must strictly prefer prices within its equilibrium support and expect to receive constant equilibrium profits over all such prices, $E\left(\pi_{i}\right)=\bar{\pi}_{i} \forall p_{i} \in\left[\underline{p_{i}}, \bar{p}_{i}\right] \forall i$ and $E\left(\pi_{i}\right)<\bar{\pi}_{i} \forall p_{i} \notin\left[\underline{p_{i}}, \bar{p}_{i}\right] \forall i$, iii) each firm's equilibrium pricing distribution must be well behaved, $F_{i}\left(\underline{p_{i}}\right)=0, F_{i}\left(\bar{p}_{i}\right)=1$ and $F_{i}^{\prime}(p) \geq 0, \forall p_{i} \in\left[\underline{p_{i}}, \bar{p}_{i}\right] \forall i$, and iv) consumers must hold correct conjectures about each firm's pricing distribution.

For what follows, define the fraction of costly-shoppers that optimally choose to first search firm $i$ as $\alpha_{i}^{*} \in[0, \alpha]$ for $i=1,2$, such that $\alpha_{1}^{*}+\alpha_{2}^{*} \leq \alpha$. Without loss of generality, Proposition 1 focuses on the case where $s_{1} \leq s_{2}$.

Proposition 1. For any $0 \leq s_{1} \leq s_{2}$, any Stage 2 equilibrium must be described by the following 8

\footnotetext{
${ }^{8}$ With the following caveat: when $\alpha_{1}^{*}=\alpha_{2}^{*}$, the expressions for $F_{1}(p)$ and $F_{2}(p)$ are defined over $p \in\left[\underline{p_{1}}, \overline{p_{1}}\right]$ rather than $p \in\left[\underline{p_{1}}, \overline{p_{1}}\right)$.
} 


$$
\begin{gathered}
F_{1}(p)=1-\left(\frac{\left(\alpha_{2}^{*}+\beta\right) \underline{p_{1}}}{\beta p}-\frac{\alpha_{2}^{*}}{\beta}\right) \quad p \in\left[\underline{p_{1}}, \bar{p}_{1}\right) \\
f_{1}\left(\bar{p}_{1}\right)=\left(\frac{\alpha_{1}^{*}-\alpha_{2}^{*}}{\alpha_{1}^{*}+\beta}\right) \\
F_{2}(p)=1-\left(\frac{\left(\alpha_{1}^{*}+\beta\right) \underline{p_{1}}}{\beta p}-\frac{\alpha_{1}^{*}}{\beta}\right) \quad p \in\left[\underline{p_{1}}, \bar{p}_{1}\right) \\
\underline{p_{1}}=\left(\frac{\alpha_{1}^{*}}{\alpha_{1}^{*}+\beta}\right) \bar{p}_{1}, \quad \bar{p}_{1}=\min \left\{r_{2}^{*}, V\right\} \\
\bar{\pi}_{1}=\alpha_{1}^{*} \bar{p}_{1}, \quad \bar{\pi}_{2}=\left(\alpha_{2}^{*}+\beta\right) \underline{p_{1}}
\end{gathered}
$$

where $r_{i}^{*}$ is the value of $r_{i}$ such that $\int_{\underline{p_{i}}}^{r_{i}}\left(r_{i}-p\right) d F_{i}(p)=s_{i}$, which for Firm 2, yields,

$$
r_{2}^{*}=\left(\frac{\beta s_{2}}{\beta+\alpha_{1}^{*} \ln \left(\alpha_{1}^{*} /\left(\alpha_{1}^{*}+\beta\right)\right)}\right)
$$

where the unique values of $\left\{\alpha_{1}^{*}, \alpha_{2}^{*}\right\}$ are given by the following when $s_{1} \in(0,((1-\alpha)+$ $\alpha \ln \alpha) V]$,

$$
\begin{array}{cc}
\alpha_{1}^{*}=\frac{s_{2}-\beta s_{1}}{s_{1}+s_{2}}, \alpha_{2}^{*}=\frac{s_{1}-\beta s_{2}}{s_{1}+s_{2}} & \text { if } s_{2} \in\left[s_{1},\left(s_{1} / \beta\right)\right) \\
\alpha_{1}^{*}=\alpha, \alpha_{2}^{*}=0 & \text { if } s_{2} \geq s_{1} / \beta
\end{array}
$$

and where the values of $\left\{\alpha_{1}^{*}, \alpha_{2}^{*}\right\}$ in any equilibrium must be such that

$$
\begin{array}{cc}
\alpha_{1}^{*}+\alpha_{2}^{*}=\alpha & \text { if } s_{2}=s_{1}=0 \\
\alpha_{1}^{*} \leq \frac{s_{2}-\beta s_{1}}{s_{1}+s_{2}}, \alpha_{2}^{*} \leq \frac{s_{1}-\beta s_{2}}{s_{1}+s_{2}} & \text { if } s_{2} \in\left[s_{1},\left(s_{1} / \beta\right)\right) \text { and } s_{1}>((1-\alpha)+\alpha \ln \alpha) V \\
\alpha_{1}^{*} \leq \alpha, \alpha_{2}^{*}=0 & \text { if } s_{2} \geq s_{1} / \beta \text { and } s_{1}>((1-\alpha)+\alpha \ln \alpha) V
\end{array}
$$

Proof. See Appendix.

Figures 1 and 2 present a graphical representation of Proposition 1 for $s_{2} \geq s_{1}$, holding constant $s_{1} \in(0,((1-\alpha)+\alpha \ln \alpha) V]^{9}$. Figure 1 illustrates the initial search behaviour of the costly-shoppers in equilibrium and Figure 2 illustrates the equilibrium price distributions ${ }^{10}$. As explained in more detail below, when $s_{2}=s_{1}$, the costly-shoppers optimally first search the firms in equal proportions, $\alpha_{1}^{*}=\alpha_{2}^{*}=(\alpha / 2)$, and the firms employ identical price distributions. However as $s_{2}$ increases, the costly-shoppers choose to first search

\footnotetext{
${ }^{9}$ Figures 1 and 2 use a set of example parameters, $s_{1}=1, V=10$ and $\alpha=\beta=0.5$.

${ }^{10}$ The equilibrium price distributions are related to Narasimhan (1988) which considers $\alpha_{1}^{*}$ and $\alpha_{2}^{*}$ as exogenous under the special case $s_{1}=s_{2}=\infty$.
} 
Firm 1 (Firm 2) in larger (smaller) proportions until the point when $s_{2} \geq\left(s_{1} / \beta\right)$, where all the costly-shoppers first search Firm $1, \alpha_{1}^{*}=\alpha$. Increases in $s_{2}$ also prompt both firms' price distributions to increase in the sense of first-order stochastic dominance (until $\bar{p}_{1}$ reaches its maximum, $V$ ). Moreover, such increases allow Firm 1 to earn higher profits and select a 'higher' price distribution than Firm 2, with positive mass at the upper price bound, $\bar{p}_{1}$.

Insert Figures 1 and 2 here.

First consider the symmetric case with $s_{2}=s_{1} \in(0,((1-\alpha)+\alpha \ln \alpha) V]$, and suppose $\alpha_{1}^{*}=\alpha_{2}^{*}=(\alpha / 2)$. As first demonstrated by Janssen et al $(2005)^{11}$, there then exists an equilibrium where the two firms use an identical pricing distribution, $F_{1}(p)=F_{2}(p)$, with identical associated reservation prices, $r_{1}^{*}=r_{2}^{*}>0$, and earn identical equilibrium profits, $\bar{\pi}_{1}=\bar{\pi}_{2}$. In setting $\bar{p}_{i}=\min \left\{r_{j}^{*}, V\right\}$, Firm $i$ can guarantee an equilibrium profit, $\bar{\pi}_{i}=(\alpha / 2) \bar{p}_{i}$, by ensuring that its share of costly-shoppers find it optimal to buy without making a second search. However, the existence of an atom of shoppers presents each firm with the incentive to undercut its rival until the lower price bound, $\underline{p_{i}}=(\alpha /(1+$ $\beta) \bar{p}_{i}$, below which, each firm would prefer to price at $\bar{p}_{i}$. The identical equilibrium pricing distributions balance these incentives by making each firm indifferent over the price support, $\left[\underline{p_{1}}, \bar{p}_{1}\right]$. For $\alpha_{1}^{*}=\alpha_{2}^{*}=(\alpha / 2)$ to be consistent with the costly-shoppers' optimal behaviour, the costly-shoppers must be willing to make a first search and indifferent between first searching Firm 1 and Firm 2. From Lemma 1, this requires $r_{1}^{*}=r_{2}^{*} \leq V$ to be true in equilibrium. From above, we know $r_{1}^{*}=r_{2}^{*}$ holds and $r_{1}^{*}=r_{2}^{*} \leq V$ can be shown to be satisfied when the level of search costs is sufficiently low, $s_{1} \leq((1-$ $\alpha)+\alpha \ln \alpha) V$. Although not shown by Janssen et al, Proposition 1 also demonstrates that this equilibrium is unique as any other division of costly-shoppers must be inconsistent in equilibrium. For example, if instead $\alpha_{i}^{*}>\alpha_{j}^{*}$, then $F_{j}(p)>F_{i}(p) \forall p \in\left(\underline{p_{1}}, \bar{p}_{1}\right)$, such that $r_{i}^{*}>r_{j}^{*}$ and the costly-shoppers would all rather first search firm $j$. Further, if $\alpha_{i}^{*}=\alpha_{j}^{*}<(\alpha / 2)$, then $r_{1}^{*}=r_{2}^{*}<V$, such that all costly-shoppers would strictly prefer to make a first search. Finally, note the special case when $s_{2}=s_{1}=0$, where Bertrand competition always ensures zero prices and profits in equilibrium, $\bar{\pi}_{i}=\bar{p}_{1}=\underline{p_{1}}=0$. Here,

\footnotetext{
${ }^{11}$ In standard search models, consumers are assumed to make their first search for free. Janssen et al (2005) first departed from this assumption, but focussed on the case where search costs were exogenous and symmetric across firms.
} 
due to the presence of the shoppers, any division of costly-shoppers is consistent with equilibrium provided $\alpha_{1}^{*}+\alpha_{2}^{*}=\alpha$, because $s_{i}=p_{i}=r_{i}^{*}=0<V \forall i$ for any value of $\left\{\alpha_{1}^{*}, \alpha_{2}^{*}\right\}$.

Second, consider the case where $s_{2}$ is significantly larger than $s_{1}$, with $s_{2} \geq\left(s_{1} / \beta\right)$ and $s_{1} \in(0,((1-\alpha)+\alpha \ln \alpha) V]$. Suppose $\alpha_{1}^{*}=\alpha$ and $\alpha_{2}^{*}=0$. In setting $\bar{p}_{1}=\min \left\{r_{2}^{*}, V\right\}$, Firm 1 can guarantee an equilibrium profit, $\bar{\pi}_{1}=\alpha \bar{p}_{1}$, by ensuring that the costly-shoppers find it optimal to buy without further searching Firm 2. Without any first searches from the costly-shoppers, Firm 2 can only gain profits by competing for the shoppers. Consequently, $p_{2} \geq \bar{p}_{1}$ is dominated. Firm 1 is willing to compete by lowering its price until a lower price bound, $\underline{p_{1}}=\alpha \bar{p}_{1}$, below which it would prefer to price at $\bar{p}_{1}$. Firm 2 will then never optimally price below $\underline{p}_{1}$. The equilibrium pricing distributions make each firm indifferent over their respective price supports, $p_{1} \in\left[\underline{p_{1}}, \bar{p}_{1}\right]$ and $p_{2} \in\left[\underline{p_{1}}, \bar{p}_{1}\right)$, and are asymmetric as shown in the right-hand case of Figure 2 . Further, it must be true that $\bar{\pi}_{2}=\beta \underline{p_{1}}$, as Firm 2 can always ensure the custom of the shoppers by pricing at $\underline{p_{1}}$. This implies $\bar{\pi}_{2}<\bar{\pi}_{1}$. For $\alpha_{1}^{*}=\alpha$ and $\alpha_{2}^{*}=0$ to be consistent with the costly-shoppers' optimal behaviour, the costly-shoppers must be willing to first search Firm 1 . From Lemma 1, this requires $r_{1}^{*} \leq r_{2}^{*}$ and $r_{1}^{*} \leq V$ to be true in equilibrium. Despite Firm 1's higher prices, one can show that $r_{1}^{*} \leq r_{2}^{*}$ is true in equilibrium if Firm 2's search cost is sufficiently large, $s_{2} \geq\left(s_{1} / \beta\right)$, and that $r_{1}^{*} \leq V$ if $s_{1} \leq((1-\alpha)+\alpha \ln \alpha) V$. Once more, this equilibrium is unique as any other division of costly-shoppers would be inconsistent with equilibrium.

Third, consider the case with intermediate value of $s_{2}$, with $s_{2} \in\left(s_{1},\left(s_{1} / \beta\right)\right)$ and $s_{1} \in\left(0,((1-\alpha)+\alpha \ln \alpha) V\right.$. Suppose $\alpha_{1}^{*}=\frac{s_{2}-\beta s_{1}}{s_{1}+s_{2}}$ and $\alpha_{2}^{*}=\frac{s_{1}-\beta s_{2}}{s_{1}+s_{2}}$, which as displayed in Figure 1, implies $\alpha_{1}^{*} \in((\alpha / 2), \alpha), \alpha_{2}^{*}=(0,(\alpha / 2))$ and $\alpha_{1}^{*}+\alpha_{2}^{*}=\alpha$. The resulting equilibrium price distributions follow a similar logic to the case above. In setting $\bar{p}_{1}=$ $\min \left\{r_{2}^{*}, V\right\}$, Firm 1 can guarantee an equilibrium profit of $\bar{\pi}_{1}=\alpha_{1}^{*} \bar{p}_{1}$ by ensuring that its share of costly-shoppers find it optimal to buy without further searching Firm 2. Again, although Firm 2 receives some costly-shoppers, it always wishes to undercut Firm 1. Firm 1 will compete until a lower bound, $\underline{p_{1}}=\left(\alpha_{1}^{*} /\left(\alpha_{1}^{*}+\beta\right)\right) \bar{p}_{1}$, and the subsequent equilibrium distributions on $p_{1} \in\left[\underline{p_{1}}, \bar{p}_{1}\right]$ and $p_{2} \in\left[\underline{p_{1}}, \bar{p}_{1}\right)$ are asymmetric as shown in the middle-case of Figure 2. Firm 2 can guarantee $\bar{\pi}_{2}=\left(\alpha_{2}^{*}+\beta\right) \underline{p_{1}}<\bar{\pi}_{1}$ by pricing at $\underline{p_{1}}$ to ensure the custom of the shoppers and its share of costly-shoppers. For $\alpha_{1}^{*}=\frac{s_{2}-\beta s_{1}}{s_{1}+s_{2}}$ and $\alpha_{2}^{*}=\frac{s_{1}-\beta s_{2}}{s_{1}+s_{2}}$ to be consistent with the costly-shoppers' optimal behaviour, the costly-shoppers must 
be willing to make a first search and be indifferent between first searching Firm 1 and Firm 2. From Lemma 1, this requires $r_{1}^{*}=r_{2}^{*} \leq V$ to be true in equilibrium. Despite Firm 1's higher prices, one can show that $r_{1}^{*}=r_{2}^{*}$ is true in equilibrium if Firm 2's search cost is relatively larger than Firm 1's, $s_{2} \in\left(s_{1},\left(s_{1} / \beta\right)\right]$, and that $r_{1}^{*}=r_{2}^{*} \leq V$ if $s_{1} \leq((1-\alpha)+\alpha \ln \alpha) V$. As above, the division of costly-shoppers is unique.

Finally, in the remaining cases where $s_{1} \leq s_{2}$ but $s_{1}>((1-\alpha)+\alpha \ln \alpha) V$, one need only show that the initial search decisions must be bounded by those found previously for the case when $s_{1}$ is smaller. In the symmetric case, $s_{1}=s_{2}$, the full participation of the costly-shoppers $\left(\alpha_{1}^{*}+\alpha_{2}^{*}=\alpha\right)$ can no longer be supported as this would imply, $r_{i}^{*}>V$, such that search would no longer be optimal. Neither, can $\alpha_{1}^{*}+\alpha_{2}^{*}=0$ be optimal (unless $\left.s_{1}=s_{2} \geq V\right)$ as then equilibrium prices would be zero and the costly-shoppers would wish to search. Instead, as shown in Janssen et al (2005, Proposition 2), the equilibrium must involve partial participation with the costly-shoppers mixing between searching and not participating in order to lower equilibrium prices to the point where $r_{i}^{*}\left(\alpha_{1}, \alpha_{2}\right)=V$ for $i=1,2$. Similarly, in the asymmetric cases, some non-participation is necessary to ensure prices are low enough to allow the costly-shoppers to be indifferent over entering the market in equilibrium. The exact level of participation is difficult to present analytically due to lack of an explicit expression for Firm 1's reservation price.

It is interesting to note that the relationship between the order of search and equilibrium prices remains contested within the literature. Consistent with our results, Arbatskaya (2007) demonstrates that prices are declining in (an exogenous) search order within a homogenous goods market where consumers' search costs are distributed with an atomless distribution, but where each consumer faces the same search cost for each firm. Other papers have shown that this relationship may be reversed. For example, Armstrong et al (2009) show that prices can be increasing in (an exogenous) search order if the firms exhibit random product differentiation. This results from the fact that the residual demand of the first searched firm can be more elastic than its rivals' due to a higher composition of 'fresh' consumers that have yet to search the entire market.

\section{Stage 1 Analysis}

This section now examines the firms' equilibrium choice of search costs. For convenience, we will maintain the notational assumption that $s_{1} \leq s_{2}$. It will also be useful to define 
$\bar{s}_{2}=[1+(\alpha / \beta) \ln \alpha] V>0$ as the value of $s_{2}$ that produces an equilibrium value of $r_{2}^{*}=V$, provided the value of $s_{1}$ is such that $\alpha_{1}^{*}=\alpha$. Firm 2 will then be said to 'fully obfuscate' if it sets $s_{2} \geq \bar{s}_{2}$ such that $r_{2}^{*} \geq V$, because the costly-shoppers will then never face a strict incentive to search it. Proposition 2 now provides the main result of the paper.

Proposition 2. There exists no equilibrium with full transparency, where $s_{1}=s_{2}=0$. Instead, there exists an infinite number of outcome-equivalent asymmetric equilibria where one firm, say Firm 2, fully obfuscates with $s_{2} \geq \bar{s}_{2}=[1+(\alpha / \beta) \ln \alpha] V>0$ and where its rival does not obfuscate, with $s_{1}=0$. Relative to no obfuscation, these equilibria yield larger profits for both firms and lower surplus for both types of consumers.

Proof. See Appendix.

Contrary to initial intuition, Proposition 2 demonstrates that competition may not be enough to ensure market transparency. Even when firms are presented with a costless opportunity to improve consumers' information, the market equilibria involve imperfect information provision. In particular, Proposition 2 suggests that information provision will be asymmetric, with one firm always choosing to fully obfuscate by deliberately increasing its cost of being searched ${ }^{12}$.

To gain an understanding for this result, first note that if neither firm obfuscates, the costly-shoppers can identify both prices costlessly and Bertrand competition ensures that both firms earn zero profits. Now imagine an increase in Firm 2's search costs, holding constant $s_{1}=0$. This increases $r_{2}^{*}$ and reduces the willingness of the costly-shoppers to visit Firm 2, providing two effects: i) rather than being indifferent between first searching Firm 1 and Firm 2, now all the costly-shoppers strictly prefer to first search Firm 1, $\alpha_{1}^{*}=\alpha$, because $r_{1}^{*}<r_{2}^{*}$ for all $s_{2}>0=s_{1}=\left(s_{1} / \beta\right)$, and ii) the costly-shoppers become more willing to buy at Firm 1 without further search, allowing Firm 1 to increase its prices, as $\bar{p}_{1}=\min \left\{r_{2}^{*}, V\right\}$. This second effect continues until the point $s_{2}=\bar{s}_{2}$, where $r_{2}^{*}=V$ and where Firm 2 is said to fully obfuscate. At such a point, Firm 1 is able to maintain the custom of all the costly-shoppers even at $p_{1}=\bar{p}_{1}=V$, to earn $\bar{\pi}_{1}=\alpha V$. This provides Firm 1 with a very weak incentive to lower its price and thereby furnishes Firm 2 with

\footnotetext{
${ }^{12} \mathrm{~A}$ further equilibrium where the firms randomise between $s_{i}=0$ and $s_{i} \geq \bar{s}_{2}$ may also exist, but it is clear that the associated profits will be weakly dominated by the profits gained within the asymmetric pure strategy equilibria.
} 
a level of market power over the shoppers who remain willing to search due to their low cost of time ${ }^{13}$. Specifically, Firm 2 can guarantee equilibrium profits, $\bar{\pi}_{2}=\beta \underline{p_{1}}=\beta \alpha V$, by pricing at $\underline{p_{1}}=\alpha V$. Consequently, the subsequent pricing equilibrium prompts both firms to use positive prices, but allows Firm 1 to set probabilistically higher prices than Firm 2, with $F_{2}(p) \geq F_{1}(p) \forall p$. Further increases in $s_{2}$ above $\bar{s}_{2}$ have no effect on equilibrium as $\bar{p}_{1}$ cannot increase beyond $V$ and so $\bar{\pi}_{1}=\alpha V>\bar{\pi}_{2}=\beta \alpha V>0$ for all $s_{2} \geq \bar{s}_{2}$ such that Firm 2 strictly prefers to break the no-obfuscation outcome by fully obfuscating ${ }^{14}$. This reduces both types of consumer surplus, expressed respectively as $C S_{C S}=V-E\left(p_{1}\right)$ and $C S_{S}=V-E\left(\min \left\{p_{2}, p_{1}\right\}\right)$, because unlike the Bertrand case, prices now become positive.

Second, consider why the decision by the costly-shoppers to first search Firm 1 after obfuscation is consistent with equilibrium. Despite higher expected prices, the costlyshoppers find it optimal to first search Firm 1 due to the offsetting factor of Firm 1's low search cost, which ensures $r_{1}^{*}=0<r_{2}^{*}, V$.

Third, consider Firm 1's incentives. Firm 1 has no strict incentive to obfuscate in addition to Firm 2. From Proposition 1, we know that selecting $s_{1}=s_{2} \geq \bar{s}_{2}$ cannot be optimal because this would induce $\pi_{1} \leq \alpha V / 2$ which is lower than the profits earned by not obfuscating, $\bar{\pi}_{1}=\alpha V$. Further, selecting $s_{1}>s_{2}$ cannot be optimal as we know that the firm with the lower search costs always earns higher profits. Now consider an increase in $s_{1}$ such that $0<s_{1}<s_{2}$. Levels of $s_{1}$ towards the upper end of this range could act to reduce demand and profits by pushing $r_{1}^{*}$ beyond $V$ and deterring the costly-shoppers from making an initial search, and even if the increase in $s_{1}$ was smaller such that costlyshopper participation was maintained, profits would only remain unchanged $^{15}$. Note also, that Firm 1 has no incentive to counter Firm 2's obfuscation strategy by perhaps, helping to inform the costly-shoppers of Firm 2's location and price, because the resulting softer

\footnotetext{
${ }^{13}$ Within the current assumptions, this is trivial as the shoppers have a zero cost of time. More generally, the incentives to obfuscate can remain as long as some non-zero proportion of shoppers are still willing to search Firm 2.

${ }^{14}$ If practical or cost constraints generate some limit to the level of obfuscation, $\widehat{s}_{2} \in\left(0, \bar{s}_{2}\right)$, then it follows that Firm 2 will simply select $s_{2}=\widehat{s}_{2}$. Prices and profits will strictly increase but by an amount less than under full obfuscation.

${ }^{15}$ This leads to the possibility of other equilibria where Firm 2 fully obfuscates and where Firm 1 obfuscates by some small amount. Such equilibria would be outcome-equivalent to those described in Proposition 1 in terms of prices and profits and would only involve lower levels of costly-shopper welfare.
} 
price competition strictly increases Firm 1's profits. This reason differs from Gabaix and Laibson (2006) where the rival firm has no incentive to inform the myopic consumers of the obfuscating firm's concealed add-on price because, even when informed, the consumers would still prefer to buy from the obfuscating firm in order to obtain a lower base price, while substituting away from the add-on.

A further overall intuition for Proposition 2 can be gained by considering the role of the shoppers. The existence of the shoppers is potentially damaging for industry profits because they generate the incentives for firms to engage in tougher price competition ${ }^{16}$. Here however, obfuscation by an individual firm can minimise this damage by sorting the consumer types across the two firms, such that its rival has a reduced incentive to compete. This logic is very similar to the mechanism that underlies standard results in vertical product differentiation (Shaked and Sutton 1982). In parallel, if consumers vary in their taste for high quality (or costs of time), a duopolist may be able to profit from choosing a lower level of quality (or higher level of search costs) than its rival.

\section{Robustness}

This section investigates the robustness of the results with regard to a number of factors: the possibility of a minimum, natural level of search costs, more than two firms, an imperfect ability of consumers to assess search costs and a situation where firms are unable to commit to an obfuscation strategy. By doing so, the section also highlights how the paper differs to Ellison and Wolitsky (2008).

5.1. Minimum market frictions. In contrast to the previous section, the 'natural' level of search costs, absent obfuscation, is unlikely to be zero in some markets. This subsection presents a more general case by assuming that firms cannot choose search costs below some minimum level, $s_{i} \geq m$ where $m \in[0, V]$. In addition to providing a comparison to Ellison and Wolitsky (2008) which assumes $m>0$, this extension also offers a useful platform for the oligopoly analysis below. Proposition 3 confirms the logic and results of Proposition 2 by suggesting that one firm always has the incentive to add to the

\footnotetext{
${ }^{16}$ Ellison's (2005) analysis of obfuscation in markets with add-ons demonstrates that firms can use the existence of shoppers (or low types in his model) to actually increase profits by creating an adverse selection effect that deters price cuts.
} 
natural level of search costs, provided Condition A holds. Condition A ensures the full participation of the costly-shoppers is optimal in equilibrium when $s_{1}=m$, and is likely to be satisfied when the fraction of costly-shoppers, $\alpha$, is relatively small or when the natural level of search costs, $m$, is low relative to $V$ (see Figure 3). It is always satisfied when $m=0^{17}$.

$$
(m / V)<(1-\alpha)+\alpha \ln \alpha
$$

Insert Figure 3 here.

Proposition 3. When Condition A holds, there exists no game equilibrium with full transparency, where $s_{1}=s_{2}=m$. Instead, there exists an infinite number of outcomeequivalent asymmetric equilibria where one firm, say Firm 2, fully obfuscates with $s_{2} \geq$ $\bar{s}_{2}=[1+(\alpha / \beta) \ln \alpha] V>m$ and where its rival does not obfuscate, with $s_{1}=m$.

Proof. See Appendix.

5.2. More than two firms. This subsection shows that the incentives for individual obfuscation can also remain in markets with a larger number of firms. Rather than taking the approach of previous results, we simply aim to characterise a set of parameters where obfuscation must form part of equilibrium behaviour. Specifically, a set of parameters is considered where a firm can profitability deviate from the no-obfuscation outcome while still ensuring the full participation of the costly-shoppers.

Proposition 4. The region of parameters where any equilibrium must involve obfuscation is non-empty for any finite number of firms if $m>0$.

Proof. See Appendix.

With a similar logic to the duopoly case, Proposition 4 demonstrates the incentives for a firm to obfuscate in order to reduce its rivals' willingness to compete for the shoppers and increase their equilibrium prices. Unlike the duopoly case however, where obfuscation was

\footnotetext{
${ }^{17}$ An equilibrium analysis outside Condition $\mathrm{A}$ is difficult due to the intractability problems caused by partial costly-shopper participation.
} 
always profitable when the natural level of search costs, $m$, was zero, profitable obfuscation now requires $m>0$. Intuitively, if $m=0$ when $n>2$ any individual increase in search costs is unable to raise prices because the remaining firms are still left to engage in Bertrand competition with each other. The same logic also rules out the profitability of obfuscation when $n=\infty$, as highlighted below. This results contrasts with Gabaix and Laibson (2006) where all firms optimally obfuscate in equilibrium by concealing their addon prices, regardless of the market structure. The difference arises because obfuscation does not rely on softening competition in their model. Instead, it acts to deceive myopic consumers in a way that is then used to compete more aggressively for sophisticated consumers.

Corollary 1. There is no strict incentive to obfuscate when $n=\infty$.

It is difficult to find further analytical results concerning the profitability of obfuscation and the number of competitors. However, simulations suggest that the region of parameters where a firm can profitability obfuscate while ensuring the full participation of the costly-shoppers appears to shrink as the number of competitors increases, (see Figure 4 in the appendix). This provides a very tentative suggestion that increases in the number of competitors might reduce the level of equilibrium search $\operatorname{costs}^{18}$. Future work aims to further investigate this issue.

5.3. Imperfect observability. Contrary to the base model, there may be circumstances where consumers are not aware of the value of $s_{i}$ until after searching firm $i$. In such cases, as considered by Ellison and Wolitzky (2008), consumers must view the firms as ex ante identical such that search order is no longer an important issue. This subsection now demonstrates that the incentive to obfuscate can remain in our model even when consumers observe firms' search costs imperfectly.

In particular, we consider equilibria where consumers can assess the market distribution of actual search costs, $\left\{s_{i}, s_{j}\right\}$, but are unable to observe the exact search cost of any

\footnotetext{
${ }^{18}$ Intuitively, this pattern derives from a well known feature of the Stahl (1989) model that shows that an increase in the number of competitors actually increases equilibrium prices because a price cut becomes less likely to win the custom of the shoppers. Thus, when $n$ is larger, obfuscation is more likely to raise prices beyond the point where the full participation of the costly-shoppers is optimal.
} 
individual firm until after searching ${ }^{19}$. Imagine Firm 2 marginally increases its search cost to $\varepsilon>0$, holding $s_{1}=0$. Costly-shoppers are only aware of $\left\{s_{i}, s_{j}\right\}=\{\varepsilon, 0\}$ such that firms' reservation prices remain unobservable. Therefore, provided their product valuation is large enough to ensure market participation, the costly-shoppers can do no better than randomising over their first search destinations, $\alpha_{1}^{*}+\alpha_{2}^{*}=(\alpha / 2)$. By doing so, the costly-shoppers learn the price and search cost of their visited firm and are able to infer the search cost of the remaining firm. As a result, the costly-shoppers that visited Firm 2 always face a weak incentive to become fully informed as they realise that they can further search Firm 1 at no extra cost. However, the costly-shoppers that first searched Firm 1 now infer that $s_{2}=\varepsilon$ and are reluctant to make a further search. Following a similar intuition to Proposition 2, this provides Firm 1 with the ability to raise prices and weakens its incentive to compete for the remaining consumers, which then allows Firm 2 to also earn positive profits. Proposition 5 follows.

Proposition 5. There exists no equilibrium with full transparency, $s_{1}=s_{2}=0$, even when search costs are imperfectly observable.

Proof. See Appendix.

5.4. The role of commitment. In many circumstances, where obfuscation is in the form of a longer-run decision variable such as location or some forms of advertising, the assumption that firms can commit to an obfuscation strategy seems reasonable. This subsection now investigates whether our results can extend to alternative market scenarios where firms do not have such an ability. Consider a game without commitment where each firm selects its price and search cost simultaneously in Stage 1, before consumers observe the level of each firm's search costs and make their search decisions in Stage 2. Proposition 6 demonstrates that the ability to commit is a crucial assumption within our paper, and forms the key difference to Ellison and Wolitzky (2008).

Proposition 6. Without pre-commitment, there exists a no-obfuscation equilibrium where $s_{1}=s_{2}=p_{1}=p_{2}=0$.

\footnotetext{
${ }^{19}$ This assumption is stronger than Ellison and Wolitzky. They assume consumers can only make conjectures about the distribution of search costs which are correct in equilibrium.
} 
Proof. See Appendix.

Without an ability to commit to a level of search costs, obfuscation cannot break the Bertrand equilibrium. Any attempt by an individual firm to profitably obfuscate by increasing its search costs and price will fail to induce an increase in rival prices and simply prompt all consumers to search and buy elsewhere.

However, Ellison and Wolitzky (2008) show how two obfuscation mechanisms can exist in such a setting if one makes some additional assumptions. In a framework where consumers are unable to observe firm's search costs such that the costly-shoppers are willing to randomise over their initial search destinations, Ellison and Wolitzky show the existence of symmetric equilibria where all firms obfuscate with positive probability. Under both mechanisms, the incentive to obfuscate arises through its effect on inflating the costly-shoppers' (expected) cost of a second search, such that an obfuscating firm can profitably increase its price (distribution) while maintaining the trade of its share of costly-shoppers. The first mechanism assumes that a consumer's total cost of search, $g(s)$, is strictly convex in the time spent searching, rather than our implicit linear assumption, $g(s)=s$. Consequently, provided the costly-shoppers find it optimal to make a first search and that $s_{j} \geq m>0$, an increase $s_{i}$ can increase the marginal cost of a second search, $g\left(s_{i}+s_{j}\right)-g\left(s_{i}\right)>0$. The second mechanism assumes that search costs are uncertain due to the existence of a common shock across all firms, $\theta$, which is unobservable to both firms and consumers. Firm $i$ can then make the (expected) cost of a second search more expensive by increasing $s_{i}$ in order to inflate the costly-shoppers' estimated value of $\theta$. Finally, note that Ellison and Wolitzky's results also differ from ours in the relationship between obfuscation and prices. After introducing costs to obfuscation, their model predicts that in order to deter further search, firms with a low price realisation can obfuscate less than firms with a high price realisation. This contrasts to our model where the obfuscating firm must select lower prices in order to compete effectively for the shoppers.

\section{Conclusion}

This paper has analysed the incentives to obfuscate in a framework where consumers can choose not only the number of firms to search, but also the order in which to search. Obfuscation by an individual firm can profitably induce consumers with high costs of time 
to search to first search the firm's now 'prominent' rival and thereby soften competition for the remaining consumers.

The paper's findings suggest a government intervention to provide better market information would improve competition and enhance consumer welfare. However, it remains unclear to what extent such an intervention would be necessary. Indeed, while it has been shown that both an obfuscating firm and its rival benefit from obfuscation, future research should aim to better understand the incentives for other market players to counter obfuscation strategies by improving consumers' information. First, in our model and in the literature as a whole, there may be incentives for a third party to sell information to costly-shoppers. Such incentives relate to the existence of intermediaries or gatekeepers, as studied by Baye and Morgan (2001). However, as argued in Ellison and Ellison (2009) any such agent has to avoid the potential paradox of being unable to sell any information if by doing so, it makes the market perfectly competitive. Second, our model presents an incentive for the shoppers to inform their fellow consumers of the obfuscating firm's location and price in order to strengthen competition. Future work would be useful in providing a fuller understanding of the effect of consumers' social networks on competition. See Galeoitti (2008) for a start on this issue.

Finally, in the light of behavioural industrial organisation, it is tempting to reinterpret the model as one in which consumers differ in their cognitive ability, rather than in their costs of time, and where firms obfuscate by making their prices harder to understand, rather than harder to observe. Such an interpretation of search costs is discussed in Ellison (2006) but it appears unconvincing in regard to the current model for several reasons. First, the assumption that search costs are a necessary pre-purchase expenditure seems less reasonable. Indeed, it might be both possible and rational for a consumer to buy a product without making the calculations to fully comprehend a price. Second, the assumption that firms can pre-commit to a level of search costs seems less reasonable as firms can often modify how a price is presented at negligible cost. Finally, the cognitive search cost interpretation appears to generate a methodological incompatibility. One must assume that a consumer must expend some costly resources to merely understand a price, while maintaining that the consumer can infer all other players' strategies and calculate an optimal strategy based on a set of reservation prices with potentially nonanalytical solutions at zero cost. While the topic of spurious market complexity is of 
huge importance, it would appear that more radical revisions to standard search models are needed for its study. Spiegler's (2006) model of obfuscation across multiple product dimensions when consumers make naive comparisons is an exciting step in this direction.

\section{REFERENCES}

[1] Arbatskaya M. (2007) "Ordered Search" RAND Journal of Economics vol.38 p.119126

[2] Armstrong M., Vickers J. and Zhou J. (2009) "Prominence and Consumer Search" RAND Journal of Economics vol.40(2) p. 209-233

[3] Athey S. and Ellison G. (2008) "Position Auctions with Consumer Search" Working Paper

[4] Bakos J.Y. (1997) "Reducing Buyer Search Costs: Implications for Electronic Marketplaces" Management Science vol.43 p.1676-1692

[5] Baye M.R., Kovenock D. and De Vries C.G. (1992) "It Takes Two to Tango: Equilibria in a Model of Sales" Games and Economic Behaviour vol.4 p.493-510

[6] Baye M.R. and Morgan J. (2001) "Information Gatekeepers on the Internet and the Competitiveness of Homogenous Product Markets" American Economic Review vol. 91 p. $454-474$

[7] Carlin B. I. (2008) "Strategic Price Complexity in Retail Financial Markets" Working Paper

[8] Ellison G. (2005) "A Model of Add-on Pricing" Quarterly Journal of Economics vol.120 p.585- 637

[9] Ellison G. (2006) "Bounded Rationality in Industrial Organization" in Advances in Economics and Econometrics: Theory and Applications, Ninth World Congress, Blundell, Newey and Persson (eds.), Cambridge University Press

[10] Ellison G. and Ellison S.F. (2009) "Search, Obfuscation and Price Elasticities on the Internet" Econometrica vol.77(2) p.427-452 
[11] Ellison G. and Wolitzky A. (2008) "A Search Cost Model of Obfuscation" Working Paper, September

[12] Gabaix X. and Laibson D. (2006) "Shrouded Attributes, Consumer Myopia, and Information Suppression in Competitive Markets" Quarterly Journal of Economics vol.121 p.505-540

[13] Galeotti A. (2008) "Talking, Searching and Pricing" Working Paper

[14] Garrod L. (2007) "Price Transparency and Consumer Naivety in a Competitive Market" Working Paper

[15] Grossman S. J. (1981) "The Role of Warranties and Private Disclosure about Product Quality" Journal of Law and Economics vol.24 p.461-483

[16] Haan M.A. and Moraga-González J.L. (2009) "Advertising for Attention in a Consumer Search Model" Working Paper

[17] Hortaçsu A. and Syverson C. (2004) "Product Differentiation, Search Costs, and Competition in the Mutual Fund Industry: A Case Study of SESP 500 Index Funds" Quarterly Journal of Economics vol. 119 p.403-456

[18] Ireland N.J. (1993) "The Provision of Information in a Bertrand Oligopoly" Journal of Industrial Economics vol.41 p.61-76

[19] Janssen M. and Moraga-González J.L. (2004) "Strategic Pricing, Consumer Search and the Number of Firms" Review of Economic Studies vol. 71 p.1089-1118

[20] Janssen M., Moraga-González J.L. and Wildenbeest M.R. (2005) "Truly Costly Sequential Search and Oligopolistic Pricing" International Journal of Industrial Organisation vol.23 p.451-466

[21] Janssen M. and Non M. (2008) "Advertising and Consumer Search in a Duopoly Model" International Journal of Industrial Organization vol.26 p.354-371

[22] Milgrom P. (1981) "Good News and Bad News: Representation Theorems and Applications" Bell Journal of Economics vol.12 p.380-391

[23] Narasimhan C. (1988) "Competitive Promotional Strategies" The Journal of Business vol.61 p.427-449 
[24] Shaked, A. and Sutton, J. (1982) "Relaxing Price Competition Through Product Differentiation" Review of Economic Studies vol.49 p.3-13

[25] Spiegler R. (2006) "Competition over Agents with Boundedly Rational Expectations" Theoretical Economics vol.1 p.207-231

[26] Stahl D. O. (1989) "Oligopolistic Pricing with Sequential Consumer Search" American Economic Review vol.79 p.700-712

[27] Varian H.R. (1980) "A Model of Sales" American Economic Review vol.70 p.651-659

[28] Weitzman M.L. (1979) "Optimal Search for the Best Alternative" Econometrica vol. 47 p. $641-654$

[29] Zettelmeyer F. (2000) "The Strategic Use of Consumer Search Cost" Working Paper 


\section{Appendix:}

\section{Proposition 1:}

Proof. In a series of steps we first demonstrate the existence of the equilibrium listed in Proposition 1 by construction, before demonstrating equilibrium uniqueness for the case where $s_{1} \in(0,((1-\alpha)+\alpha \ln \alpha) V]$.

Step 1. It is easy to verify that the proposed pricing distributions are well-behaved, with $F_{i}\left(\underline{p_{1}}\right)=0, F_{i}^{\prime}(p)>0 \forall p \in\left[\underline{p_{1}}, \bar{p}_{1}\right) \forall i=1,2, F_{2}\left(\bar{p}_{1}\right)=1$, and $F_{1}\left(\bar{p}_{1}\right)+f_{1}\left(\bar{p}_{1}\right)=1$.

Step 2. In any potential equilibrium with $\alpha_{1}^{*} \geq \alpha_{2}^{*}$ define the following exhaustive cases: i) $\alpha_{1}^{*} \geq \alpha_{2}^{*}>0$, ii) $\alpha_{1}^{*}>\alpha_{2}^{*}=0$ or iii) $\alpha_{1}^{*}=\alpha_{2}^{*}=0$. For such cases to be consistent with consumers' optimal search strategies, Lemma 1 suggests the following must be true in equilibrium. (See the text for more explanation). Case i) requires $r_{1}^{*}=r_{2}^{*} \leq V$. Case ii) requires $r_{1}^{*} \leq r_{2}^{*}$ and $r_{1}^{*} \leq V$. Case iii) requires $r_{1}^{*}, r_{2}^{*}>V$, because the costly-shoppers must strictly prefer to remain out of the market.

Step 3. Knowing this, one can now verify that each firm can do no better than pricing with its proposed distribution to earn its proposed equilibrium profits, given the equilibrium behaviour of its rival and the consumers. Noting from Lemma 1, that the $\alpha_{i}^{*}$ costly-shoppers that have decided to first search firm $i$ will only buy without further search to firm $j$ if $p_{i} \leq \min \left\{r_{j}^{*}, V\right\}$, one can describe the expected profits of each firm by the following. (Recall $\bar{p}_{1}=\min \left\{r_{2}^{*}, V\right\}$ ).

$$
\begin{gathered}
E\left(\pi_{1}(p) \mid F_{2}(p)\right)=\left\{\begin{array}{cc}
0 & \text { if } p_{1}>\bar{p}_{1} \\
p_{1}\left[\alpha_{1}^{*}+\beta\left(1-F_{2}(p)\right)\right] & \text { if } p_{1} \in\left[\underline{p_{1}}, \bar{p}_{1}\right] \\
p_{1}\left[\alpha_{1}^{*}+\beta\right] & \text { if } p_{1}<\underline{p_{1}}
\end{array}\right. \\
E\left(\pi_{2}(p) \mid F_{1}(p)\right)=\left\{\begin{array}{cc}
0 & \text { if } p_{2}>\bar{p}_{1} \\
\left(\left(\alpha_{2}^{*}+\beta\right) / 2\right) f_{1}\left(\bar{p}_{1}\right) & \text { if } p_{2}=\bar{p}_{1} \\
p_{2}\left[\left(\alpha_{2}^{*}+\beta\right)\left(1-F_{1}(p)\right)\right] & \text { if } p_{2} \in\left(\min \left\{r_{1}^{*}, V\right\}, \bar{p}_{1}\right) \\
p_{2}\left[\alpha_{2}^{*}+\beta\left(1-F_{1}(p)\right)\right] & \text { if } p_{2} \in\left[\underline{p_{1}}, \min \left\{r_{1}^{*}, V\right\}\right] \\
p_{2}\left[\alpha_{2}^{*}+\beta\right] & \text { if } p_{2}<\underline{p_{1}}
\end{array}\right.
\end{gathered}
$$

For Firm 1, it is easy to check that $E\left(\pi_{1}(p) \mid F_{2}(p)\right)=\bar{\pi}_{1}=\alpha_{1}^{*} \bar{p}_{1}$ for $p_{1} \in\left[\underline{p_{1}}, \bar{p}_{1}\right]$ and $E\left(\pi_{1}(p) \mid F_{2}(p)\right)<\bar{\pi}_{1}$ for $p_{1} \notin\left[\underline{p_{1}}, \bar{p}_{1}\right]$. To perform a similar check for Firm 2 requires us to consider two cases. First, suppose $\alpha_{2}^{*}=0$. Then it follows that $E\left(\pi_{2}(p) \mid F_{1}(p)\right)=\bar{\pi}_{2}=\beta \underline{p_{1}}$ 
for $p_{2} \in\left[\underline{p_{1}}, \bar{p}_{1}\right)$ and $E\left(\pi_{2}(p) \mid F_{1}(p)\right)<\bar{\pi}_{2}$ for $p_{2} \notin\left[\underline{p_{1}}, \bar{p}_{1}\right)$. Second, suppose $\alpha_{2}^{*}>0$. From Step 2, it must then be true that $\min \left\{r_{1}^{*}, V\right\}=\min \left\{r_{2}^{*}, V\right\}=\bar{p}_{1}$. Then it follows that $E\left(\pi_{2}(p) \mid F_{1}(p)\right)=\bar{\pi}_{2}=\left(\alpha_{2}^{*}+\beta\right) \underline{p_{1}}$ for $p_{2} \in\left[p_{1}, \bar{p}_{1}\right)$ and $E\left(\pi_{2}(p) \mid F_{1}(p)\right)<\bar{\pi}_{2}$ for $p_{2} \notin\left[p_{1}, \bar{p}_{1}\right)$.

Step 4. The equilibrium reservation prices can be constructed by inserting the appropriate equilibrium values into $\int_{\underline{p_{i}}}^{r_{i}}\left(r_{i}-p\right) d F_{i}(p)=s_{i}$, or equivalently and more simply, $\int_{\underline{p_{i}}}^{r_{i}} F_{i}(p) d p=s_{i}$. Through simplification, this can offer an explicit expression for $r_{2}^{*}=\beta s_{2} /\left(\beta+\alpha_{1}^{*} \ln \left(\alpha_{1}^{*} /\left(\alpha_{1}^{*}+\beta\right)\right)\right)$, but not for $r_{1}^{*}$.

We now check that the initial search behaviour of the costly-shoppers, $\left\{\alpha_{1}^{*}, \alpha_{2}^{*}\right\}$ is consistent with equilibrium. This is done by considering each scenario in turn.

Step 5a. When $s_{2} \in\left[s_{1},\left(s_{1} / \beta\right)\right)$ and $s_{1} \in(0,((1-\alpha)+\alpha \ln \alpha) V]$, Proposition 1 suggests $\alpha_{1}^{*}=\frac{s_{2}-\beta s_{1}}{s_{1}+s_{2}}$ and $\alpha_{2}^{*}=\frac{s_{1}-\beta s_{2}}{s_{1}+s_{2}}$ such that $\alpha_{1}^{*}+\alpha_{2}^{*}=\alpha$ and $\alpha_{1}^{*} \geq \alpha_{2}^{*}>0$. From Step 2, this requires $r_{1}^{*}=r_{2}^{*} \leq V$ to be true in equilibrium. To check $r_{1}^{*}=r_{2}^{*}$ holds $^{20}$, note that $F_{1}(p)=F_{2}(p)+\left(\frac{\left(\alpha_{2}^{*}-\alpha_{1}^{*}\right)}{\beta}\right)+\left(\frac{\left(\alpha_{1}^{*}-\alpha_{2}^{*}\right) \underline{p_{1}}}{\beta p}\right)$ which, together with the definition, $s_{2}=\int_{\underline{p_{1}}}^{r_{2}} F_{2}(p) d p$, yields $s_{2}+\int_{\underline{p_{1}}}^{r_{2}}\left(\frac{\left(\alpha_{2}^{*}-\alpha_{1}^{*}\right)}{\beta}\right)+\left(\frac{\left(\alpha_{1}^{*}-\alpha_{2}^{*}\right) \underline{p_{1}}}{\beta p}\right) d p=\int_{\underline{p_{1}}}^{r_{2}} F_{1}(p) d p$. By decomposing the right-hand side into $\int_{r_{1}}^{r_{2}} F_{1}(p) d p+\int_{p_{1}}^{r_{1}} F_{1}(p) d p=\int_{r_{1}}^{r_{2}} F_{1}(p) d p+s_{1}$ one can then obtain $\int_{r_{1}}^{r_{2}} F_{1}(p) d p=s_{2}\left(\frac{\alpha_{2}^{*}+\beta}{\alpha_{1}^{*}+\beta}\right)-s_{1}$. It then follows that $r_{1}^{*}=r_{2}^{*}$ iff $s_{2}\left(\frac{\alpha_{2}^{*}+\beta}{\alpha_{1}^{*}+\beta}\right)=s_{1}$. Further, when $\alpha_{1}^{*}+\alpha_{2}^{*}=\alpha,\left\{\alpha_{1}^{*}, \alpha_{2}^{*}\right\}$ are uniquely determined by $\alpha_{1}^{*}=\frac{s_{2}-\beta s_{1}}{s_{1}+s_{2}}$ and $\alpha_{2}^{*}=\frac{s_{1}-\beta s_{2}}{s_{1}+s_{2}}$. For $\alpha_{1}^{*}+\alpha_{2}^{*}=\alpha$ to be optimal, we require $\min \left\{r_{1}^{*}, r_{2}^{*}\right\} \leq V$. To show this is true in equilibrium when $s_{1} \leq((1-\alpha)+\alpha \ln \alpha) V$, we need only ensure that $r_{2}^{*} \leq V$ when $s_{2}=\left(s_{1} / \beta\right)$ as one can verify that $\delta r_{2}^{*} / \delta s_{2}>0 \forall s_{2} \in\left(s_{1},\left(s_{1} / \beta\right)\right]$. This then follows trivially from the fact that $\alpha_{1}^{*}=\alpha$ when $s_{2}=\left(s_{1} / \beta\right)$, such that $r_{2}^{*}=\beta s_{2} /(\beta+\alpha \ln \alpha)$.

Step 5b. When $s_{2} \in\left[s_{1},\left(s_{1} / \beta\right)\right)$ and $s_{1}>((1-\alpha)+\alpha \ln \alpha) V$, Proposition 1 suggests $\alpha_{1}^{*} \leq \frac{s_{2}-\beta s_{1}}{s_{1}+s_{2}}$ and $\alpha_{2}^{*} \leq \frac{s_{1}-\beta s_{2}}{s_{1}+s_{2}}$. From Step 5a, we know that such a level of search costs may be inconsistent with $\alpha_{1}^{*}=\frac{s_{2}-\beta s_{1}}{s_{1}+s_{2}}$ and $\alpha_{2}^{*}=\frac{s_{1}-\beta s_{2}}{s_{1}+s_{2}}\left(\operatorname{such}\right.$ that $\left.\alpha_{1}^{*}+\alpha_{2}^{*}=\alpha\right)$ in equilibrium because cases can then exist where $r_{1}^{*}=r_{2}^{*}>V$. In such cases, either $s_{1}>V$, such that search can never be optimal and $\alpha_{1}^{*}=\alpha_{2}^{*}=0$ must form part of equilibrium, or $s_{1} \in(((1-\alpha)+\alpha \ln \alpha) V, V]$. In this latter case, we know $\alpha_{i}^{*}=0$ cannnot be true because this would imply $r_{i}^{*}<V$ such that search would become optimal. Instead, any equilibrium must involve a lower level of market participation with costly-shoppers mixing

\footnotetext{
${ }^{20}$ I thank John Vickers for suggesting this step.
} 
between searching and not participating in order to lower the firms' reservation prices to a level equal to $V$.

Step 6a. When $s_{2} \geq\left(s_{1} / \beta\right)$ and $s_{1} \in(0,((1-\alpha)+\alpha \ln \alpha) V]$, Proposition 1 suggests $\alpha_{1}^{*}=\alpha, \alpha_{2}^{*}=0$. From Step 2, this requires $r_{1}^{*} \leq r_{2}^{*}$ and $r_{1}^{*} \leq V$ to be true in equilibrium. To check $r_{1}^{*} \leq r_{2}^{*}$ holds, we know from the result in Step $5 \mathrm{a}, \int_{r_{1}}^{r_{2}} F_{1}(p) d p=s_{2}\left(\frac{\alpha_{2}^{*}+\beta}{\alpha_{1}^{*}+\beta}\right)-s_{1}$, that $r_{1}^{*} \leq r_{2}^{*}$ iff $s_{2}\left(\frac{\alpha_{2}^{*}+\beta}{\alpha_{1}^{*}+\beta}\right) \geq s_{1}$. Further, when $\alpha_{1}^{*}=\alpha$, it follows that $r_{1}^{*} \leq r_{2}^{*}$ iff $s_{2} \geq\left(s_{1} / \beta\right)$. For $\alpha_{1}^{*}=\alpha$, we also require $r_{1}^{*} \leq V$. To show this is true in equilibrium when $s_{1} \leq((1-\alpha)+\alpha \ln \alpha) V$, define $\bar{s}_{2}=[1+(\alpha / \beta) \ln \alpha] V$ as the value of $s_{2}$ that generates $r_{2}^{*}=V$ when $\alpha_{2}^{*}=\alpha$. It follows that $r_{1}^{*} \leq V$ for $s_{2} \in\left(\left(s_{1} / \beta\right), \bar{s}_{2}\right]$ as then $r_{2}^{*} \leq V$. It also follows for $s_{2}>\bar{s}_{2}$, because $r_{1}^{*}\left(s_{2}\right)=r_{1}^{*}\left(\bar{s}_{2}\right) \forall s_{2} \geq \bar{s}_{2}$ as $\bar{p}_{1}=V$, and $r_{1}^{*}\left(\bar{s}_{2}\right) \leq r_{2}^{*}\left(\bar{s}_{2}\right)=V$ iff $\bar{s}_{2} \geq\left(s_{1} / \beta\right)$, or on rewriting, iff $s_{1} \leq((1-\alpha)+\alpha \ln \alpha) V$.

Step 6b. When $s_{2} \geq\left(s_{1} / \beta\right)$ and $s_{1}>((1-\alpha)+\alpha \ln \alpha) V$, Proposition 1 suggests $\alpha_{1}^{*}<\alpha, \alpha_{2}^{*}=0$. From Step 6a, we know that such a level of search costs is inconsistent with $\alpha_{1}^{*}=\alpha$ in equilibrium because this would imply $V<r_{1}^{*} \leq r_{2}^{*}$. For $s_{1}>V$, clearly $\alpha_{1}^{*}=\alpha_{2}^{*}=0$ is optimal. For $s_{1} \in(((1-\alpha)+\alpha \ln \alpha) V, V]$, we know $\alpha_{1}^{*}=0$ cannot be true in equilibrium this would imply $r_{1}^{*}<V$ such that search would be optimal. Consequently, any equilibrium must involve a lower level of market participation with the costly-shoppers mixing between searching Firm 1 with some probability, $\widehat{\alpha}_{1}^{*}<\alpha$, and not participating, such that $r_{1}^{*}\left(\widehat{\alpha}_{1}^{*}\right)=V$.

Step \%. Finally, note the special case when $s_{1}=s_{2}=0$. Bertrand competition must ensure that $\underline{p_{1}}=\bar{p}_{1}=0$ is always true in equilibrium regardless of costly-shopper behaviour. This implies $r_{1}^{*}=r_{2}^{*}=0<V \forall\left\{\alpha_{1}^{*}, \alpha_{2}^{*}\right\}$ such that any costly-shopper division is consistent with equilibrium, provided $\alpha_{1}^{*}+\alpha_{2}^{*}=\alpha$.

Step 8. To establish uniqueness when $s_{1} \in(0,((1-\alpha)+\alpha \ln \alpha) V]$, first note that for any given $\left\{\alpha_{i}^{*}, \alpha_{j}^{*}\right\}$, the equilibrium pricing distributions are unique. This follows from Baye et al (1992) which shows that games of this sort can display a continuum of pricing equilibria when $n>2$, but only a single pricing equilibrium when $n=2$. Indeed, one can see that here by observing that $\left\{F_{1}(p), F_{2}(p)\right\}$ are uniquely determined by $E\left(\pi_{i}(p) \mid F_{j}(p)\right)=\bar{\pi}_{i}$ for $i=1,2$ as listed above. Second, in the case when $s_{1} \in(0,((1-\alpha)+\alpha \ln \alpha) V]$, note from above that the values of $\left\{\alpha_{1}^{*}, \alpha_{2}^{*}\right\}$ that are consistent with the pricing equilibrium are uniquely determined for any $s_{i} \leq s_{j}$. Finally, when $s_{1}=s_{2}=0$, although the costlyshopper division in not unique, the zero pricing equilibrium is, such that all agents' payoffs 
are uniquely determined.

Proposition 2. There exists no equilibrium with full transparency, where $s_{1}=s_{2}=0$. Instead, there exists an infinite number of outcome-equivalent asymmetric equilibria where one firm, say Firm 2, fully obfuscates with $s_{2} \geq \bar{s}_{2}=[1+(\alpha / \beta) \ln \alpha] V>0$ and where its rival does not obfuscate, with $s_{1}=0$. Relative to no obfuscation, these equilibria yield larger profits for both firms and lower surplus for both types of consumers.

Proof. Given $s_{1}=0$, Firm 2's equilibrium profits, $\bar{\pi}_{2}=\left(\alpha_{2}^{*}+\beta\right) \underline{p_{1}}$ can be expanded to $\bar{\pi}_{2}=\left(\alpha_{2}^{*}+\beta\right)\left(\frac{\alpha_{1}^{*}}{\alpha_{1}^{*}+\beta}\right) \min \left(\frac{\beta s_{2}}{\beta+\alpha_{1}^{*} \ln \left(\alpha_{1}^{*} /\left(\alpha_{1}^{*}+\beta\right)\right)}, V\right)$ by using the results of Proposition 1. By noting that i) $\bar{\pi}_{2}=0$ when $s_{2}=0$ and ii) $\alpha_{1}^{*}=\alpha, \alpha_{2}^{*}=0$ for all $s_{2}>\left(s_{1} / \beta\right)=0$, Firm 2's profits can be further displayed as follows.

$$
\bar{\pi}_{2}\left(s_{2} \mid s_{1}=0\right)= \begin{cases}0 & \text { if } s_{2}=0 \\ \left(\frac{\beta^{2} \alpha s_{2}}{\beta+\alpha \ln \alpha}\right) & \text { if } s_{2} \in\left(0, \bar{s}_{2}\right) \\ \beta \alpha V & \text { if } s_{2} \geq \bar{s}_{2}\end{cases}
$$

One can first observe that $s_{1}=s_{2}=0$ can never be an equilibrium because Firm 2 can earn strictly positive profits by selecting $s_{2}>0$. To show that there exists a continuum of equilibria with $s_{1}=0$ and $s_{2} \geq \bar{s}_{2}$ note that $\bar{\pi}_{2}\left(s_{2} \mid s_{1}=0\right)$ is strictly increasing in $s_{2} \in\left(0, \bar{s}_{2}\right]$. Further, Firm 2 will prefer to fully obfuscate by setting any $s_{2} \geq \bar{s}_{2}$ rather than setting $s_{2}=0$ as $\bar{\pi}_{2}\left(s_{2} \geq \bar{s}_{2} \mid s_{1}=0\right)>0$. Given $s_{2} \geq \bar{s}_{2}$, we know that $s_{1}=0$ is a best response for Firm 1 as it is weakly dominant to set $s_{1} \in[0,((1-\alpha)+\alpha \ln \alpha) V]$ in order to earn $\bar{\pi}_{1}=\alpha_{1}^{*} \bar{p}_{1}=\alpha V$. This follows from Proposition 1 which suggests that full participation cannot be sustained for $s_{1}>\left(((1-\alpha)+\alpha \ln \alpha) V\right.$. Specifically, given $s_{2} \geq \bar{s}_{2}$, $\bar{\pi}_{1}\left(s_{1}=s_{2}\right) \leq \alpha V / 2$, ii $) \bar{\pi}_{1}\left(s_{1}>s_{2}\right) \leq \beta \alpha V$ and iii $) \bar{\pi}_{1}\left(s_{1} \in\left(((1-\alpha)+\alpha \ln \alpha) V, s_{2}\right)\right) \leq \alpha V$. Across the continuum, the equilibria are outcome-equivalent because we know that the equilibrium price distributions are independent of $s_{2} \geq \bar{s}_{2}$, and so are the payoffs for the firms, the costly-shoppers and the shoppers, denoted respectively as $\bar{\pi}_{1}=\alpha V$, $\bar{\pi}_{2}=\beta \alpha V$, $C S_{C S}=V-E\left(p_{1}\right)$ and $C S_{S}=V-E\left(\min \left\{p_{2}, p_{1}\right\}\right)$. Finally, both firms earn profits that are strictly larger than those obtainable under a no-obfuscation outcome, as $\alpha V>\beta \alpha V>0$, and both consumer types earn lower expected surplus. This last point follows as one can still use the same expressions for consumer surplus for the no-obfuscation outcome 
and then show that contrary to the no-obfuscation equilibrium, full obfuscation generates $\underline{p_{1}}=\alpha V>0$

Proposition 3: When Condition A holds, there exists no game equilibrium with full transparency, where $s_{1}=s_{2}=m$. Instead, there exists an infinite number of outcomeequivalent asymmetric equilibria where one firm, say Firm 2, fully obfuscates with $s_{2} \geq$ $\bar{s}_{2}=[1+(\alpha / \beta) \ln \alpha] V>m$ and where its rival does not obfuscate, with $s_{1}=m$.

Proof. Condition A implies $m=s_{1}<((1-\alpha)+\alpha \ln \alpha) V$ such that full participation is guaranteed, $\alpha_{1}^{*}+\alpha_{2}^{*}=\alpha \forall s_{2}$. Condition A also ensures that $\bar{s}_{2}>\left(s_{1} / \beta\right)$, such that $\alpha_{1}^{*}=\alpha$ is consistent with equilibrium when $s_{2} \geq \bar{s}_{2}$. The proof can then proceed with the same series of steps as Proposition 2, with the following modifications due to the fact that it may no longer be true that $s_{1}=\left(s_{1} / \beta\right)=m=0$. Given $s_{1}=m$, Firm 2's profits can now be expressed as below. Full obfuscation is a best response as profits are strictly increasing in $s_{2} \in\left(m, \bar{s}_{2}\right]$ and $\bar{\pi}_{2}\left(s_{2} \geq \bar{s}_{2}\right)>\bar{\pi}_{2}\left(s_{2}=m\right)$. The surplus of the costlyshoppers is now $C S_{C S}=V-m-E\left(p_{1}\right)$ for $s_{2}=m$ or $s_{2} \geq \bar{s}_{2}$. Obfuscation then lowers both forms of consumer surplus because one can show that the symmetric no-obfuscation price distribution is stochastically dominated by the price distributions of both firms in the obfuscation equilibria, $F(p) \geq F_{2}(p) \geq F_{1}(p)$.

$$
\bar{\pi}_{2}\left(s_{2} \mid s_{1}=m\right)= \begin{cases}\frac{\alpha \beta m}{2 \beta+\alpha \ln \left(\frac{\alpha}{1+\beta}\right)} & \text { if } s_{2}=m \\ \left(\frac{\beta s_{1}\left(s_{2}-\beta s_{1}\right)}{\beta\left(s_{1}+s_{2}\right)+\left(s_{2}-\beta s_{1}\right) \ln \left(\frac{s_{2}-\beta s_{1}}{s_{2}(1+\beta)}\right)}\right) & \text { if } s_{2} \in(m,(m / \beta)] \\ \left(\frac{\beta^{2} \alpha s_{2}}{\beta+\alpha \ln \alpha}\right) & \text { if } s_{2} \in\left((m / \beta), \bar{s}_{2}\right) \\ \beta \alpha V & \text { if } s_{2} \geq \bar{s}_{2}\end{cases}
$$

Proposition 4. The region of parameters where any equilibrium must involve obfuscation is non-empty for any finite number of firms.

Proof. First we show that there can exist no game equilibrium with $s_{i}=m \forall i=$ $\{1, \ldots n\}$ when Conditions B and C hold. Define Condition B as $B=1-\int_{0}^{1} \frac{d y}{1+((1-\alpha) / \alpha) n y^{n-1}}-$ $\left(\frac{(n-1)-\alpha(n-2)}{n(1-\alpha)}\right)\left[1+\left(\frac{1}{n-2}\right)\left(\psi-(n-1) \psi^{1 /(n-1)}\right]>0\right.$ and Condition $\mathrm{C}$ as $0<(m / V) \leq$ 
$\left[1+\left(\frac{1}{n-2}\right)\left(\psi-(n-1) \psi^{1 /(n-1)}\right)\right]$ where $\psi=\alpha /((n-1)-\alpha(n-2))$. In the symmetric case, when $s_{i}=m \forall i=\{1, \ldots n\}$, Janssen et al (2005) establish that individual firm profits are no larger than $\bar{\pi}_{i}=(\alpha / n)\left(s /\left(1-\int_{0}^{1} \frac{d y}{1+((1-\alpha) / \alpha) n y^{n-1}}\right)\right)$. Now consider a deviation by firm $n$ such that $s_{n}>V$ and $s_{a}=m$ for $a=\{1,2, \ldots n-1\}$. If i) $r_{a}^{*} \leq V$ and ii) $r_{a}^{*}<r_{n}^{*}$, then $\alpha_{a}^{*}=\alpha /(n-1)$ and $\alpha_{n}^{*}=0$ must be consistent with optimal costly-shopper behaviour. It then follows from the logic of Proposition 1 that $\bar{\pi}_{a}=(\alpha /(n-1)) \bar{p}_{a}$, with $\bar{p}_{a}=\min \left\{r_{n}^{*}, r_{a}^{*}, V\right\}=r_{a}^{*}$, and $\bar{\pi}_{n}=\beta \underline{p_{a}}$, where $\underline{p_{a}}=\psi r_{a}^{*}$. One can then note that $F_{a}(p)=1-\left(\underline{p_{a}} / p\right)^{1 /(n-1)}$ and by using $\int_{\underline{p_{a}}}^{r_{a}} F_{a}(p) d p=m$, $r_{a}^{*}=\left(m /\left[1+\left(\frac{1}{n-2}\right)\left(\psi-(n-1) \psi^{1 /(n-1)}\right)\right]\right.$. The Conditions then ensure that the deviation is profitable (Condition B together with $0<(m / V)$ ) and that the assumption of $r_{a}^{*} \leq V$ still holds (the latter part of Condition C). It follows trivially that $r_{a}^{*}<r_{n}^{*}$. Given a sufficiently small, but positive level of $\alpha$, Conditions B and C then require $(n-1) / n<1$ and $0<(m / V) \leq 1$, such that Proposition 4 follows.

Proposition 5. There exists no equilibrium with full transparency, $s_{1}=s_{2}=0$, even when search costs are imperfectly observable.

Proof. Following the text, one need only demonstrate that $\bar{\pi}_{2}>0$ when $s_{1}=0$ and $s_{2}=\varepsilon>0$. In any equilibrium (for small enough $\varepsilon$ ), the costly-shoppers can do no better than dividing their first searches such that $\alpha_{1}^{*}+\alpha_{2}^{*}=(\alpha / 2)$ as $r_{1}^{*}$ and $r_{2}^{*}$ remain unobservable. On visiting Firm 1, half of the costly-shoppers infer $s_{2}=\varepsilon$ which implies $r_{2}^{*}>0$. Consequently, Firm 1 can always guarantee a maximin equilibrium profit of $\bar{\pi}_{1}=(\alpha / 2) \min \left\{r_{2}^{*}, V\right\}>0$ and will be unwilling to price below $\underline{p_{1}}=\bar{\pi}_{1}$. Firm 2 can then always price at $p_{2}=p_{1}$ to guarantee $\bar{\pi}_{2}=(1-(\alpha / 2)) p_{1}>0$, ensuring that $s_{1}=s_{2}=0$ cannot be an equilibrium.

Proposition 6. Without pre-commitment, there exists a no-obfuscation equilibrium where $s_{1}=s_{2}=p_{1}=p_{2}=0$.

Proof. In such an equilibrium, the costly-shoppers must correctly infer $p_{1}=p_{2}=0$ and $r_{1}^{*}=r_{2}^{*}=0$ after observing $s_{1}=s_{2}=0$. The costly-shoppers will then find it optimal to make a first search as $\min \left\{r_{1}^{*}, r_{2}^{*}\right\}<V$ and buy without making a second search as $p_{i} \leq r_{j}^{*}=0$, such that $\bar{\pi}_{i}=0$. To rule out any profitable deviations from equilibrium, note that any deviation by firm $i,\left\{s_{i}^{\prime}, p_{i}^{\prime}\right\}$ can only be profitable if $p_{i}^{\prime}>0$. Given $p_{i}^{\prime}>0$ 
the following will be true for any $s_{i}^{\prime}$, holding $s_{j}=p_{j}=0$ constant: i) all shoppers will buy from firm $j$, ii) any costly-shoppers that first visit firm $j$ will continue to buy without further search and iii) any costly-shoppers that first visit firm $i$ will make a second search and buy from firm $j$ as $p_{i}^{\prime}>r_{j}^{*}=p_{j}=0$, such that $\bar{\pi}_{i}\left(p_{i}^{\prime}>0\right)=0$.

Figure 1: Equilibrium initial search behaviour to Firm 1 (top), $\alpha_{1}^{*}$, and Firm 2, $\alpha_{2}^{*}$, where $\alpha=0.5$ and $s_{1}=1$ such that $s_{1} / \beta=2$

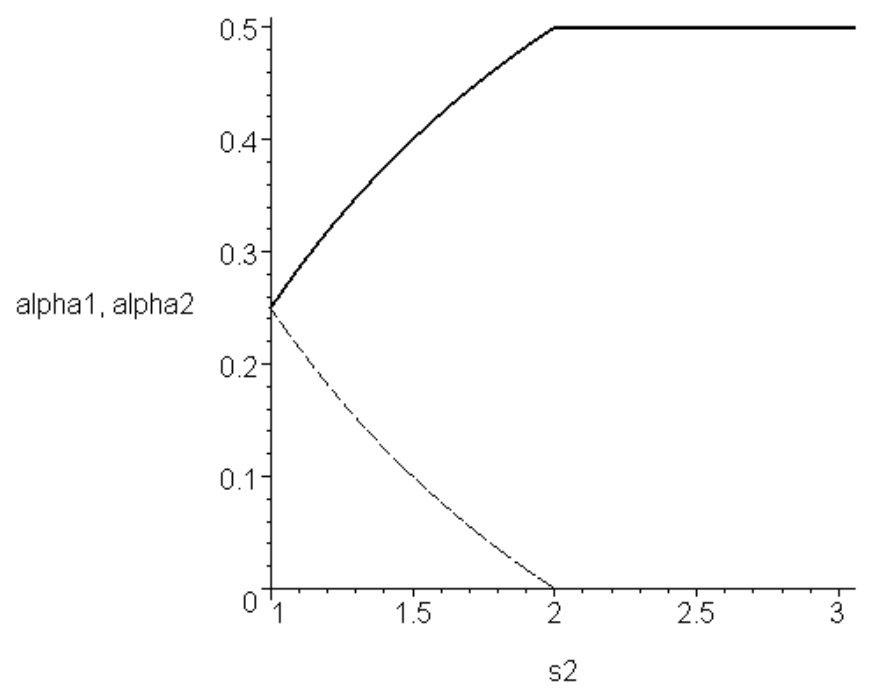


Figure 2: Equilibrium Price Distributions: $F_{i}(p)$ when $s_{2}=s_{1}$ (left), $F_{2}(p)$ and $F_{1}(p)$ when $s_{2}=0.75\left(s_{1} / \beta\right)>s_{1}$ (second from left and middle), $F_{2}(p)$ and $F_{1}(p)$ when $s_{2} \geq$ $\left(s_{1} / \beta\right)$ (second from right and right)

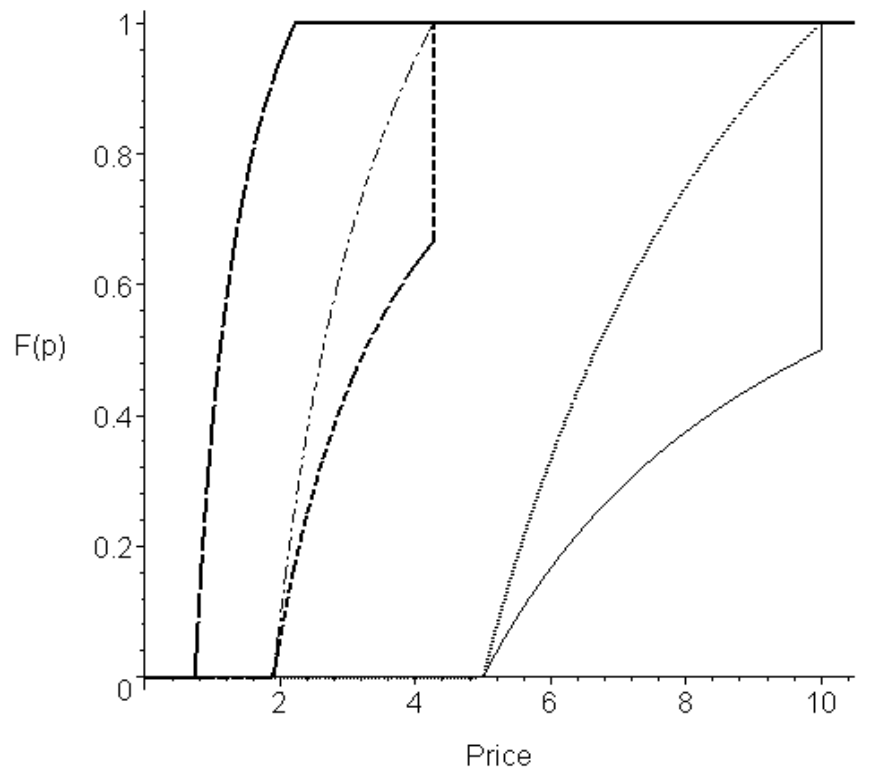

Figure 3: Condition A

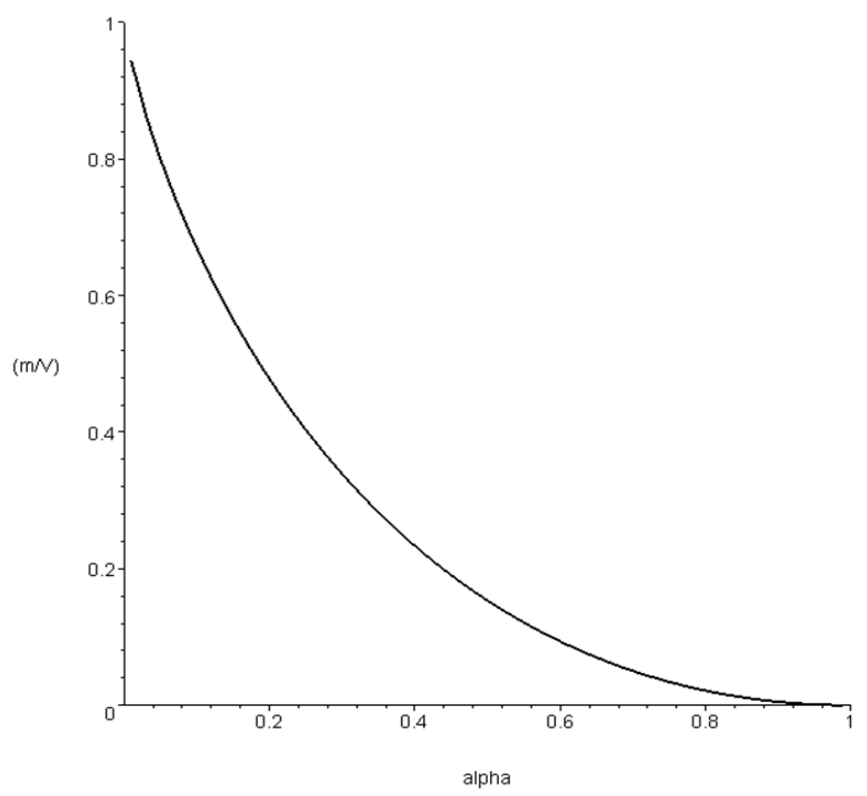


Figure 4: Simulations of Conditions B and C for $n=3$ (top), 10, 20, 50 and 200
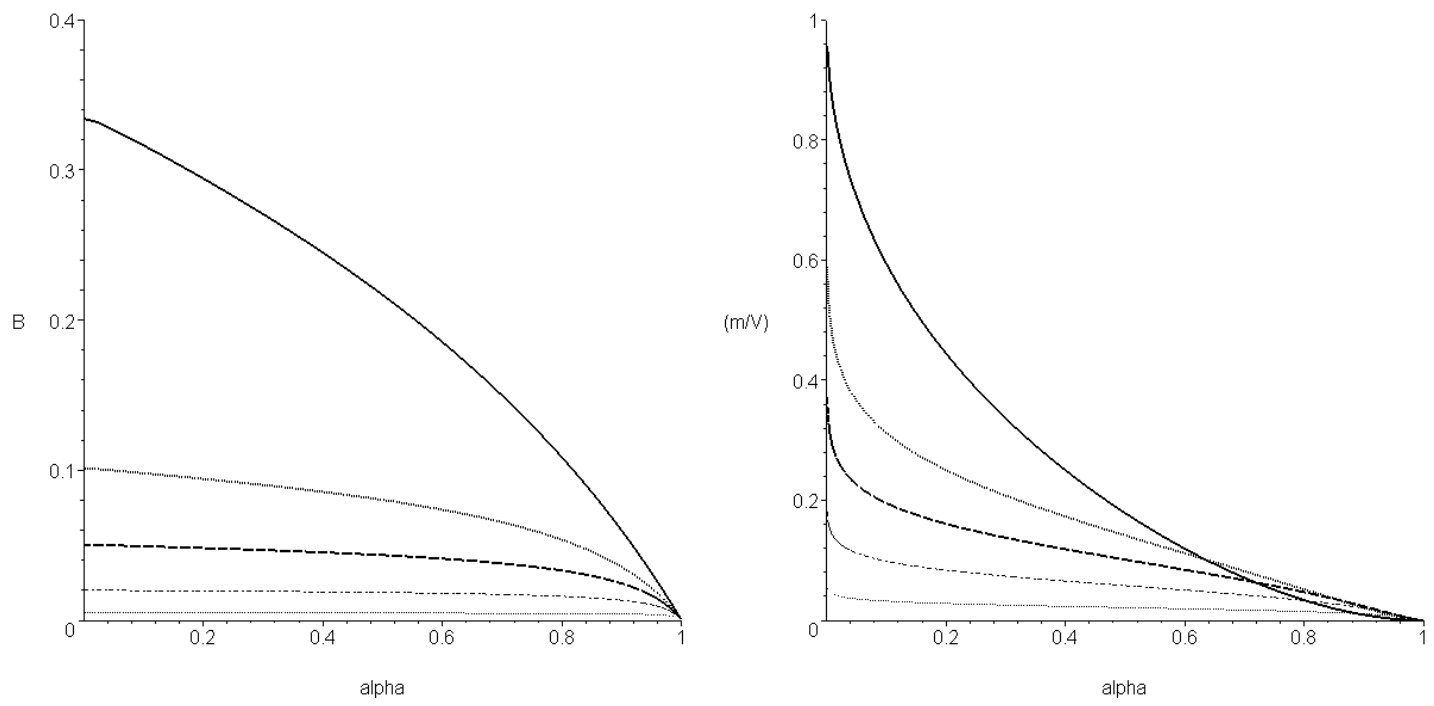